\title{
Turismo, cultura e patrimônio: Sobre os usos dos espaços da cidade
}

\author{
Tourism, culture and heritage: About the uses of spaces of the city
}

\footnotetext{
1 Jornalista, com especialização em filosofia pela Universidade de Brasília. Mestre em Turismo pela Universidade de Brasília.E-mail: inesulhoa@uol.com.br

2 Doutora em artes pela Université Paris I- Panthéon Sorbonne. Professora no Programa de Pós-Graduação em Turismo da Universidade de Brasília. E-mail: karinadias.net@gmail.com
} 


\title{
Resumo
}

Neste artigo, as autoras examinam a relação turismo, cultura e patrimônio e seus usos nos espaços das cidades, bem como analisam as relações de poder dentro da sociedade em que o turismo muitas vezes está relegado à subordinação das leis de mercado de consumo. $\mathrm{O}$ artigo procura contemplar pontos importantes para a compreensão dos processos que determinam como o espaço produzido historicamente pode condicionar a apropriação e o uso dos lugares.

Palavras-chave: Turismo. Cultura. Patrimônio. Cidade.

\begin{abstract}
In this article, the authors examine the relationship tourism, culture and heritage, and its uses in areas of the city, as well as analyzes the relations of power within society in which tourism is often relegated to the subordination to the laws of the consumer market. The article seeks to address important points to understand the processes that determines how the space historically produced may affect the ownership and use of places.
\end{abstract}

Keywords: Tourism. Culture. Heritage. City.

\section{Introdução}

Embora os estudos do turismo ainda se encontrem incipientes e ainda está em curso uma busca de paradigma, podemos dizer que, atualmente, a área vem ganhando destaque, principalmente pela sua dimensão econômica, mas também pelas questões sociais nela imbricadas, como um fenômeno sociocultural, em que também pode ser observada a produção de culturas. Temos, assim, que enxergar nele um sentido mais amplo e complexo do que a simples prática ou sob uma perspectiva comercial, como muitos preferem vê-lo, pois envolve uma rede de pessoas e serviços, mesmo aqueles que não participam diretamente de sua realização.

Nessa perspectiva, é possível entender o turismo como ciência, "compreendido a partir de sua totalidade histórica, com sua dimensão explicativa, partindo da economia, da 
política, da cultura e dos aspectos sociais que cercam uma comunidade", como bem analisa Magalhães (2008, p.96). A questão para o autor é entender o turismo a partir de sua multidisciplinaridade, que tem em seus aspectos teóricos os instrumentais para a leitura do real e, assim, ver como o turismo se insere no mundo do trabalho, tendo em vista que conceitos como ócio, lazer e tempo livre estão presentes nas relações de produção e nos conflitos de classe.

Similarmente, Moesch defende que "a realidade desse fenômeno, sua prática social, exige uma nova práxis, um novo saber-fazer, com uma nova referência, conjugando objeto, teoria, método e prática" (2002, p. 27). Para a autora, criar uma ciência do turismo significa buscar dar conta da complexa multidisciplinaridade do que é humano. Por isso, Moesch propõe criar novos comunicantes entre ciências e disciplinas que se apropriam do fenômeno turístico, como exemplos do real, simplificando-o e adaptando-o. Segundo ela,

O real do turismo é uma amálgama na qual tempo, espaço, diversão, economia, tecnologia imaginário, comunicação, diversão e ideologia são partes de um fenômeno pós-moderno, em que o protagonista é o sujeito, seja como produtor ou consumidor da prática social turística. Não nego a contingência material do turismo em sua expressão econômica, mas esta ocorre historicamente, em espaços e tempos diferenciados, cultural e tecnologicamente construídos, a serem irrigados com o desejo de um sujeito biológico. Sujeito objetivado, fundamental para a compreensão do fenômeno turístico como prática social, e subjetivado em ideologias, imaginários e necessidade de diversão, na busca do elo perdido entre prosa e poesia (MOESCH, 2002, p.31).

Para além da necessidade de construir um novo campo teórico, se levarmos em conta que o turismo, que opera também como "consumidor de culturas", pode possibilitar o entendimento da realidade, como a tradição e a história, torna-nos possível, então, compreender como os interesses econômicos sobressaem-se e confirmam que, em grande parte, iniciativas de preservação de alguns locais se observam pura e simplesmente em atendimento às exigências da indústria do turismo, que, conforme constata Lemos (2010, p.30), "vai forjando nos sítios visitados imagens, às vezes ressuscitadas, definidoras de peculiaridades culturais regionais aptas a estar sempre despertando a curiosidade dos viajantes ávidos de novidades", reificando 3

3 Segundo o Dicionário do pensamento marxista (BOTTOMORE (Ed)1988, p. 314), reificação é o ato (ou resultado do ato) de transformação das propriedades, relações e ações humanas em propriedades, relações e ações de coisas produzidas pelo homem, que se tornaram independentes (e que são imaginadas como originalmente independentes) do homem e governam sua vida. Significa igualmente a transformação dos seres humanos em seres semelhantes a coisas, que não se comportam de forma humana, mas de acordo com as leis do mundo das coisas. A reificação é um caso "especial" de alienação, sua forma mais radical e generalizada, característica da moderna sociedade capitalista. 
as práticas turísticas, tanto por parte da indústria do turismo, quanto pelos próprios consumidores da prática, os turistas.

\section{0 turismo e as leis de mercado do consumo}

O turismo, de acordo com Lemos (2010), floresce em volta de bens culturais paisagísticos e arquitetônicos preservados, e, hoje, cada vez mais, vai exigindo a criação de mais cenários, de mais exotismos [provocando quadros artificiais, como os tantos resorts espalhados pela costa brasileira], modificando paisagens. Nessa lógica [da exploração capitalista] está fortemente entronizada a comercialização da cultura, que passa a ser vista e explorada pelas indústrias cultural e do turismo, como instrumento para a obtenção de lucro, ou o uso da cultura "como conveniência" (YÚDICE, 2004).

Para Harvey, a indústria do conhecimento e do patrimônio, a produção cultural, a arquitetura de grife e o cultivo de juizos estéticos distintivos "se tornaram poderosos elementos constitutivos da política do empreendedorismo urbano, em muitos lugares" (2006, p. 233). Assim, o consumidor do turismo fica ao sabor da manipulação operada pela indústria, que, interessada apenas no valor econômico que a atividade traz, desde tempos imemoriais, promove a segmentação do setor, como estratégia competitiva no mercado, tais como: turismo verde, turismo de aventura, turismo de negócios, turismo de saúde, turismo da terceira idade, entre outros.

Mas foi com a Revolução Industrial - que marcou o início do capitalismo industrial e modificou as relações sociais e territoriais, intensificando o fenômeno da urbanização - que o turismo inicia sua atividade com esse caráter de consumo voltado para atender as necessidades econômicas do mercado. Hoje, ele pode ser visto como "uma criação da sociedade de consumo, que, a partir da importância do lazer na sociedade atual, passa a vender o turismo ou a comercializar a viagem como um novo produto, nos moldes de uma sociedade de consumo, atrelado, portanto, às leis de mercado" (SIQUEIRA, 2005, p. 64).

É justamente na (re)afirmação da sociedade de consumo, proporcionada pelo capitalismo, que surge também a cultura de massa, imposta pela indústria cultural, que, por sua vez, impulsiona o turismo também de massa, que, em parte, é uma opção da classe trabalhadora em busca do lazer em tempos de férias remuneradas. Esse contexto se afirmou na divisão tempo de trabalho-tempo livre, que surgiu a partir da lógica do domínio do capital em meados do século 18 na Inglaterra, com a Revolução Industrial, e que se expandiu a outros países no século 19. Segundo Siqueira $(2005$, pp. 41, 45): 
Ao se tornarem livres para trabalhar como força de trabalho para os donos do capital e dos meios de produção (as máquinas, o local, a matéria-prima), os antigos camponeses ou artesãos tornam-se livres, também, para serem consumidores das agora mercadorias. [...] Mas como a lógica capitalista do lucro ainda impera, estamos todos aprisionados à lógica do tempo de trabalho-tempo livre, porque o motor das sociedades capitalistas continua sendo a geração do lucro.

Na transição das sociedades pré-capitalistas para o capitalismo, conforme observa Siqueira, o próprio tempo passou a ser comprado e vendido, espelhado na famosa frase de Benjamim Franklin de que "tempo é dinheiro" - o ócio se transformou em lazer. Segundo a autora, antes produzia-se para viver e não para acumular ou se ter um excedente e as várias atividades da vida conviviam de maneira bastante integrada (trabalho, religiosidade, diversão, ócio, festa). No capitalismo, porém, a vida passa a se estruturar nessa nova divisão [de tempo] e o trabalhador será submetido a uma severa disciplina.

Nesse contexto, em que o turismo pode ter um caráter supérfluo e à medida que amadurecemos a compreensão do papel contingente da indústria do conhecimento e do patrimônio e da produção cultural voltada para o entretenimento de massa, assinalamos como a produção destrutiva do capital pode se expressar de múltiplas formas, inclusive na prática turistica, como assinala Boaventura de Sousa Santos (2010, p. 110):

Tal como para Marx a alienação assentava sobretudo na "estúpida compulsão do trabalho", talvez a nossa assente, mais do que em qualquer inculcação ideológica, "na estúpida compulsão do consumo". Aliás, as duas compulsões estão hoje mais interpenetradas do que nunca. Dantes, o operário procurava que o seu tempo livre fosse o contrário do trabalho. Hoje, o tempo livre é cada vez mais semeIhante ao tempo de trabalho. E não me refiro apenas ao tempo homogêneo e abstrato que, tal como o do trabalho, domina o turismo organizado. Refiro-me ao tempo do cotidiano, ao jogging, ao exercício fisico, à maquilagem, à aparência física cada vez mais importantes como forças produtivas do trabalhador. (grifos do autor).

As inevitáveis transformações provocadas pela expansão do modo de produção capitalista, que foram se reproduzindo no século 20, fizeram com que a cultura urbano-industrial, dominante neste modo de produção se impusesse sobre as demais culturas, conforme assinala Siqueira (2005). Como a concepção de turismo está ligada a movimento, a deslocamentos, consequentemente, esse fenômeno vai criar novas necessidades, provocar mudanças e, assim, alterar a configuração das cidades e a sua expansão para a prática da atividade turística, provocada também pela indústria cultural. 
Assim, pode-se verificar o caráter contingente da acumulação do capital na criação de grandes cidades e sua rápida urbanização, pela ruptura de fronteiras e a consequente concentração no espaço de forças produtivas e do poder político e econômico, acentuadas pelo impacto das politicas neoliberais, mais recentemente. Esses são sinais do gradativo processo de globalização e acumulação de capital, que se estabeleceu em nível mundial, como profetizaram Marx e Engels, ainda em 1848, no Manifesto Comunista (2007, p. 43):

Impelida pela necessidade de mercados sempre novos, a burguesia invade todo o globo terrestre. Necessita estabelecer-se em toda parte, explorar em toda parte, criar vínculos em toda parte.

Pela exploração do mercado mundial, a burguesia imprime um caráter cosmopolita à produção e ao consumo em todos os países. [...] Ao invés das antigas necessidades, satisfeitas pelos produtos nacionais, surgem novas demandas, que reclamam para sua satisfação os produtos das regiões mais longínquas e de climas os mais diversos. No lugar do antigo isolamento de regiões e nações auto-suficientes, desenvolvem-se um intercâmbio universal e uma universal interdependência das nações. E isto se refere tanto à produção material como à produção intelectual. As criações intelectuais de uma nação tornam-se patrimônio comum.

Ademais, a reflexão e o debate sobre as cidades revelam simultaneamente a crescente necessidade de rever conceitos, tal como a globalização (e seu uso político), e a emergência de valorização do lugar ou dos lugares como reveladores das realidades sociais. De acordo com Lemos, é preciso entender a cidade como um artefato, como um bem cultural de um povo. Mas, segundo ele, "um artefato que pulsa, que vive, que permanentemente se transforma, se autodevora e expande em novos tecidos recriados para atender a outras demandas sucessivas de programas em permanente renovação" (2010, p. 48).

\section{Na dinâmica das cidades, cultura, patrimônio e turismo se revelam}

Se a cidade é obra dos homens, seu cenário está sempre se modificando, conjugado às forças sociais que nela se interagem pelas relações cotidianas, afinal, ela "constitui o espaço da concentração, da população, dos instrumentos de produção, do capital, dos prazeres e das necessidades" (MARX e ENGELS, 2002, p. 55). Kevin Lynch, ao traçar a fisionomia das cidades, afirma a importância de sua imagem como elemento de orientação e identificação de seus moradores com elas e como a paisagem urbana também é algo a ser visto e lembrado. "Cada cidadão", diz ele, "tem vastas associações com alguma parte de sua cidade, e a imagem de cada um está impregnada de lembranças e significados" (2010, p. 1). As formas da cidade, 
assim como os objetos, não são, segundo Lynch, só passíveis de serem vistos, mas, principalmente, de se fazerem presentes e nítidos aos sentidos.

A imagem da cidade é alinhavada em meio à inventividade dos que a habitam, pois o mundo dos homens, de acordo com o pensamento marxiano, é resultado da atividade dos próprios homens. Assim, nessa paisagem urbana, não somos meros observadores, somos parte. Por isso, a importância de percebermos a cidade como símbolo, onde inscrevemos nossas lembranças e nossas emoções. Portanto, é onde se dão relações de identidade entre seus habitantes e que se reproduzem por todo o espaço urbano, pois "as imagens habituais do mundo exterior são partes inseparáveis do nosso eu" (HALBWACHS, 2011, p. 157).

Diz o sociológo francês Michel Maffesoli (2010) que uma cidade não é composta somente dos esboços e desenhos das ruas e da arquitetura edificada, ela é mesclada também de fantasia, mistérios e interpretações que seus habitantes fazem dela. A cidade é então um espaço construído por sensações, odores, ruídos, lugares de encontros constitutivos dessa teatralidade cotidiana, que faz dela, segundo Maffesoli (2010, p. 243), "um objeto animado, uma materialidade dotada de vida", pois a ideia de cidade não é restrita a uma identidade política e social, mas ampliada a uma representação cultural, depositária também de memórias.

Uma cidade que é sempre labiríntica porque se compõe do que vemos e do que invemos, dos caminhos percorridos e daqueles outrora sonhados. Uma cidade-paisagem cartografada em seus múltiplos pontos de vista, cambiante, sempre em constituição. Pensar a cidade, é (re)desenhar constantemente o seu contorno. A cidade tem a medida de nosso olhar, a escala de nossas percepções (DIAS, 2010).

Como as cidades ocupam papel central na produção dos espaços, com todas as suas representações culturais, elas também difundem ideias, comportamentos, valores e formas de lazer. Porém, sabe-se que inventar sempre uma nova necessidade humana é a chave para a expansão do capitalismo sobre a vida urbana e a cultura que ela engendra. Por isso, os espaços da cidade podem ser considerados um campo onde forças antagônicas se encontram: é onde a geopolítica do capitalismo impõe a sua força, incorporando e criando valor a espaços que passam por transformações profundas, mediados por interesses de grupos, dando a sua lógica a territórios turísticos e constituindo, assim, ícones culturais, como tantos espalhados pelas cidades do mundo. Ao valorizar os espaços urbanos como destinação turística, os agentes capitalistas, mais particularmente a indústria turística, que se aproveitam de uma necessidade do homem em se (re)aproximar da natureza, intensificam a atividade social dos mercados e das pessoas, por caminhos nem sempre politicamente 
corretos, com vistas ao processo de acumulação.

Evidentemente, a percepção dos sujeitos sociais não está imune ao entendimento de que o Estado e o mercado são os atores hegemônicos no processo de produção de uma lógica que pode, também ser destrutiva para o próprio desenvolvimento do turismo. Nessa perspectiva, concordamos com Moesch (2008, p.11), quando ela afirma que o desenvolvimento do conhecimento do turismo ocorre condicionado ao funcionamento da sociedade contemporânea, cuja importância "está atrelada à magnitude das cifras econômicas que cruzam as fronteiras internacionais" por meio da atividade turística.

A partir da leitura que Moesch faz a respeito do contexto social onde o saber turístico se desenvolve, fica claro o uso do paradigma marxista para explicar que a sociedade divide-se em duas partes, que, segundo a autora, estão dialeticamente relacionadas, na qual sua força motriz é a luta de classes.

Dentro desse paradigma, o turismo é um campo produtivo, localizado na infraestrutura da sociedade, portanto determinado pelas forças de mercado - leia-se luta entre as diferentes classes sociais - reduzido a produto de consumo, acessível às classes economicamente dominantes (2008, p.11).

Interessante observar que as críticas de Karl Marx e Friedrich Engels às condições de exploração contidas no modo de produção capitalista e à força da ideologia do capital traziam embutidas também a preocupação com o mundo do lazer, o mundo do "não trabalho" (tempo livre, ócio), da classe operária. Em A Ideologia alemã,eles destacam que,

na sociedade comunista, em que cada um não tem uma esfera de atividade exclusiva, mas pode se aperfeiçoar no ramo que lhe agradar, a sociedade regulamenta a produção geral, o que cria para mim a possibilidade de hoje fazer uma coisa, amanhã outra, caçar de manhã, pescar na parte da tarde, cuidar do gado ao anoitecer, fazer crítica após as refeições, a meu bel-prazer, sem nunca me tornar caçador, pescador ou crítico (2002, p. 28).

Na perspectiva dessa dinâmica nas cidades, é possível entender que o ócio e o lazer são produtores também do movimento espacial porque favorecem conhecer novos lugares, culturas e pessoas, que impulsionam o lado subjetivo da demanda turística. Milton Santos (2004) defendeu a ideia do espaço como resultado de uma relação indissociável entre sistemas e objetos, "casando duas coisas, ação e materialidade". Para ele, o que realmente entra na dialética social "não é o espaço tal como definido antes, como materialidade, mas o espaço vivido, usado pelos homens" (2004, p. 25). Por isso, 
o transitar de pessoas que buscam no turismo o entretenimento e a cultura, colocando-as em contato com outras expressões culturais e outros modos de vida, pode ser visto como um atributo da cidadania, por afirmar os direitos culturais e (re)afirmar que o espaço vivido compõe-se pelas práticas espaciais cotidianas e é, antes de tudo, social. A cultura vista assim como condição da própria existência humana e revelada no encontro e na troca de conhecimento leva o homem a encontrar sentido em sua existência e no mundo que o rodeia (ULHÔA, 2013).

Daí que emerge a urgência de ver a cidade, sistema dinâmico e complexo, não apenas como uso de um mercado global, em que a técnica da informação "tem um papel determinante sobre o uso do tempo, permitindo, em todos os lugares, a convergência dos momentos, assegurando a simultaneidade das ações" (SANTOS, 2011, p. 25), mas também entrever nela o poder da cultura como aglutinadora de pessoas e propulsora do desenvolvimento material e humano da sociedade, que, juntamente com o entretenimento, pode possibilitar novas formas de se praticar o turismo.

Para a leitura interpretativa dos lugares da cidade como possibilidades do turismo, recorremos a Gastal e Moesch, para quem as pessoas moradoras ou usuárias das cidades fazem parte dos fluxos que percorrem os espaços citadinos, devendo-se incentivá-las a viver a sua cidade e desfrutá-la, para além de suas rotinas. Assim, essas pessoas tornar-se-íam turistas em sua própria cidade [turismo cidadão], cujos deslocamentos são cobertos de subjetividade, pois possibilitam, de acordo com as autoras, "afastamentos concretos e simbólicos do cotidiano, implicando, portanto, novas práticas e novos comportamentos diante da busca do prazer" (2007, p. 11).

Para Gastal e Moesch, olhar a cidade com maior cuidado "não é mais uma tarefa exclusiva dos turistas que a percorrem. Mesmo para os moradores das cidades, a sua complexidade coloca, cada vez mais, maiores desafios. Decifrá-los é fundamental para sobreviver e viver nas cidades com qualidade" (ibidem, p.19). Essa possibilidade de experienciar, vivenciar e conviver práticas sociais, culturais e turísticas na própria cidade pode, de acordo com as autoras, se dar até mesmo no mesmo bairro em que a pessoa habita ou a visitar um outro bairro de sua cidade, o que pode significar um espaço, mas também um tempo, diferente daquele do cotidiano de quem se desloca. "E isso [a experiência desse turista cidadão] ocasiona surpresa, mobiliza sentimentos e comportamentos" (ibidem, p. 12).

Por essa razão, Gastal e Moesh chamam a atenção para uma postura cidadã, em que comunidades locais podem aprender a valorizar seus recursos naturais e culturais, segundo elas, desenvolvendo maior sentimento de pertencimento e, conse- 
quentemente, elevando seu grau de cidadania, ou seja, podem se tornar "protagonistas nos processos de decisão sobre o tipo de turismo e de turistas com os quais estão dispostos a compartilhar seu próprio espaço de vivência" (ibidem, p. 16).

No entendimento das autoras, levando em conta que as cidades, cada vez mais, são resultado da rede de processos simbólicos, de comportamentos e culturas, que acontecem em seu interior e abrigam experimentações, o constante exercício do conviver com a diversidade aceleraria e transformaria a ideia de cidadania. Isso é o que possibilitaria perceber que para viver outros cenários não seria mais necessário sair dos limites urbanos, "pois estes se tornaram o território da multiplicidade, permitindo ao indivíduo ser turista mesmo sem abandonar seu território" (ibidem, p. 37). Assim, se estaria migrando de um conceito de turismo marcado pelas distâncias espaciais para um conceito que priorizasse a sua prática, como o percorrer tempos-espaços diferentes dos rotineiros. Turismo seria, então, "menos o percurso no espaço, para tornar-se um percurso por tempos-espaços, em especial culturais, diferentes daqueles a que se esteja habituado, com ênfase nas vivências e experiências" (ibidem, p. 37).

Na reflexão ora proposta, Gastal e Moesch defendem a noção de cidadania associada ao turismo e às políticas públicas, pois, segundo elas, ao se ver o turismo também como a possibilidade de mediação, pode-se chegar às suas possibilidades como importante contributo na construção da cidadania e, avançando na cidadania, na figura do turista cidadão. Ou seja, "a cidadania, se associada ao turismo, encaminharia outras possibilidades de construção do sujeito histórico, aquele em condições de se expressar e de se apropriar das suas circunstâncias espaciais e temporais, seja como sujeito histórico urbano, seja como sujeito histórico planetário" (ibidem, p. 56).

Para esse novo exercício de cidadania, as autoras argumentam, em torno do conceito de turista cidadão, envolvendo o habitante que desenvolve um relacionamento diferente com o local onde mora no seu tempo de lazer, que:

para o cidadão turista, os fixos que compõem a cidade deixam de ser desconhecidos. O território torna-se familiar e, nele e com ele, constrói-se relação de pertencimento e identificação, pois se passa a compartilhar seus códigos e, de posse dos mesmos, a situar a própria subjetividade em relação aos fixos presentes no urbano (ibidem, p. 60).

A partir dessa análise, podemos dizer que o turismo, ao ser pensado não somente para o visitante, mas também para o morador, aparece como elemento particularizador quando aplicado para uma reflexão sobre as inter-relações entre cultura e turismo, pois "se a cultura incorpora a noção de aglutinadora da vida em sociedade, 
ela explica porque, sob este prisma, pode ser considerada como um dos principais insumos ao fazer turístico" (GASTAL, 2008, p.114).

A necessidade de procurar entender a cultura e sua importância social e política, indissociáveis da transmissão de conhecimento e de experiências de pensamento nas relações sociais, deve considerar que a cidade é lugar de apropriação, onde agem forças sociais diferenciadas no constructo das significações e dos bens simbólicos, revelando patrimônios que consistiram apenas das possibilidades de transformação da realidade, pois a definição de patrimônio "passou a ser pautada pelos referenciais culturais dos povos, pela percepção dos bens culturais nas dimensões testemunhais do cotidiano e das realizações intangíveis" (PELLEGRINI e FUNARI, 2009, p.32).

Também, como bem destaca José Luiz dos Santos, "a discussão sobre cultura pode nos ajudar a pensar sobre nossa própria realidade social. De fato, ela é uma maneira estratégica de pensar sobre nossa sociedade, e isso se realiza de modos diferentes e às vezes contraditórios" (2003, p. 9). Inserido no contexto social, o homem é capaz de criar representações simbólico-sociais que se voltam para a interação social. Nesse universo, alguns indivíduos produzem símbolos; outros são receptores, assimilam e se aproximam daquilo que os identificam.

Contudo, sabe-se que, na sociedade capitalista, a maior parte do tempo livre das pessoas é dedicada ao entretenimento, não como elemento ativo, mas passivo diante do que lhes oferecem os modernos meios de comunicação de massa, a exemplo dos programas sensacionalistas e de péssimo gosto a que se dedica a televisão brasileira, carregados de valores falsos e abertos à mediocridade, como uma forma de dominação e de construção de uma hegemonia, deturpando o próprio conceito de cultura. Esses meios de comunicação, invertidamente ao seu papel social, ao invés de motivar na população a busca efetiva por cultura, utiliza-se do potencial consumidor dos cidadãos para exercer um poder controlador e manipulador sobre os valores, gostos e preferências dos indivíduos, o que facilita a dominação econômica e cultural.

Para essa discussão, não poderemos nos furtar de trazer ao debate as relações de poder dentro de uma sociedade ou entre sociedades. Isso porque, como dimensão do processo social, conforme José Luiz Santos, "a cultura registra as tendências e conflitos da história contemporânea e suas transformações sociais e políticas. Além disso, a cultura é um produto da história coletiva por cuja transformação e por cujos benefícios as forças sociais se defrontam" (2003, p. 80).

Acreditamos que, mais do que um exercício de reflexão, essas questões podem 
conduzir a um rico debate teórico, no qual é possível considerar a cultura como direito de todos os cidadãos, "porque, no exercício do direito à cultura, os cidadãos, como sujeitos sociais e políticos, se diferenciam, entram em conflito, comunicam e trocam suas experiências, recusam formas de cultura, criam outras e movem todo o processo cultural" (CHAUÍ, 2006, p. 138). Mas, além disso, a estrutura da sociedade deve possibilitar a todos os cidadãos o acesso a esses direitos, com o aval do Estado e a consequente mobilização dos setores sociais.

Em face disto, é que não podemos deixar de considerar que também o campo da cultura, com seu lugar destacado na atualidade, não escapa das tensões e impactos provocados pelo poder hegemônico do capitalismo e dos seus efeitos de dominação e controle, que se fazem sentir nas práticas de um mercado, que tudo transforma em mercadoria, consumo e consumidores e que procura, cada vez mais, impor limites à autonomia e emancipação da sociedade e ao papel exercido pelo Estado. Antonio Albino Rubim (2009), um pensador da cultura e da sociedade, observa, em consonância com o pensamento de Pierre Bourdieu, que um campo social é sempre um campo de forças, onde, segundo ele, "existem elementos de agregação e complementariedade, mas também de disputa e conflito: hegemonias e contra-hegemonias, enfim". Para ele, é a partir desse momento e movimento, que a cultura passa a ser percebida como esfera social determinada, e, portanto, a ser estudada em sua singularidade.

Portanto, problematizar a cultura como fator essencial da prática e da reflexão sobre o turismo, faz-nos entender que "ao usufruirmos formas singulares de celebração e conhecimento, nós retomamos parte de nossas identidades comuns" (PELLEGRINI e FUNARI, 2008, p. 8), que são continuamente (re)construídas pelos sujeitos na complexidade das situações sociais cotidianas. Desse ponto de vista, Gastal $(2002$, p. 69) lembra que se o binômio turismo-cultura "constituía-se na manifestação que levou os primeiros pensadores do turismo a criar a categoria turismo cultural para designar uma das motivações dos viajantes nas suas decisões sobre os destinos a serem buscados", hoje, segundo a autora, esse mesmo binômio passa a exigir novos enfoques. Ou seja, para além do romantismo de viagens ou em seu aspecto mercadológico, ou em que se verifica a força econômica e social da atividade turística, a cultura, no dizer de Gastal, deve ser deslocada da função secundária a que era submetida por agentes de viagem, como simples inspiradora de deslocamentos, para "o eixo que envolve desde a formatação dos produtos turísticos" [desde sua concepção e planejamento], até "suas implicações sociais em termos de identidade e memória" (ibidem, p. 70).

Esse pode ser um aspecto importante para o turismo atual se for levado em conta o debate que se coloca entre a cidade como espetáculo (que, associado a setores 
de marketing e de captação de recursos para a realização de megaeventos, pode atrair turismo de massa) e a cidade que dá o sentido social a seus bens materiais e simbólicos.

Sabe-se também que toda prática social e cultural é simbolicamente marcada, principalmente se ela é resultado da ação e da liberdade criativa de sujeitos, que, independentes da indústria cultural, promovem a cultura, associando-a a ações sociais e comunitárias não com o propósito de produzir cultura apenas como entretenimento para atrair turismo, mas para promover acesso do cidadão aos bens e serviços da cultura.

Nessas condições, tendo o espaço como instrumento de realizações do homem, seria o caso de se indagar sobre o significado da cidadania, sem perder de vista os direitos que o termo abrange, incluído aí a cultura. Ou seja, a cidadania só pode ser afirmada se, por extensão, estiver garantidos tanto os direitos do homem como os direitos sociais e culturais, pois todos os cidadãos, independente do seu nível social, têm direito a consumir cultura. Trazemos aqui também a aguda percepção de Chauí sobre a questão do que vem a ser cidadania cultural. Em essência, seu argumento é o seguinte: a cultura não se reduz ao supérfluo, ao entretenimento, aos padrões de mercado. Para ela, a cultura se realiza como direito de todos os cidadãos:

direito a partir do qual a divisão social das classes ou a luta de classes possa manifestar-se e ser trabalhada porque, no exercício do direito à cultura, os cidadãos, como sujeitos sociais e políticos, se diferenciam, entram em conflito, comunicam e trocam suas experiências, recusam formas de cultura, criam outras e movem todo o processo cultural.

Afirmar a cultura como um direito é opor-se à política neoliberal, que abandona a garantia dos direitos, transformando-os em serviços vendidos e comprados no mercado e, portanto, em privilégios de classe (2006, p. 138).

Portanto, afirmar a cultura como um direito e opor-se à política neoliberal, que a transforma em privilégio de classe, é fazer entrar em cena os atores, os sujeitos sociais e políticos, para a consagração da cidadania. Afinal, cidadania é "uma lei da sociedade que, sem distinção, atinge a todos e investe cada qual com a força de se ver respeitado contra a força, em qualquer circunstância" (SANTOS, 2007, p. 19). Assim, percebemos que cidadania e cotidiano são, igualmente, a base para a reprodução da vida na cidade. Ambos os termos trazem em si a ideia de movimento, de mudanças que se operam na cidade por intermédio dos múltiplos sujeitos fazendo o acontecer histórico. 


\section{Considerações finais}

A prática do turismo, que se revela muito mais além de ser uma das engrenagens do capitalismo, promove a fuga do estresse e possibilita a busca do novo, do belo, do prazer, com a afirmação, do consumidor, do seu direito à cultura, pode, então, proporcionar ao cidadão explorar e fruir o que as cidades oferecem em termos de lazer e de cultura no tempo livre do trabalho. Como atividade cada vez mais intensa, conjugada a vários fatores de dinamismo da sociedade, pode-se, na busca de novas modalidades do tempo livre, ter o turismo presente no cotidiano, pois está nele [cotiano] o próprio construir de nossa história, que se forma no nosso mover-se no mundo e nas relações com o mundo.

Podemos dizer que o espaço produzido historicamente pode condicionar a apropriação e o uso dos lugares e, assim, proporcionar novas necessidades e novos desejos, pois a sociedade se realiza no espaço e a partir dela é que se pode compreendê-lo, conforme ensina Milton Santos (2009). Para ele, o espaço nada mais é do que a soma dos resultados da intervenção humana sobre a terra.

E, ao (re)inventar o seu cotidiano, o habitante pode experimentar as ruas de sua cidade. Ser flâneur", "sair quando nada nos força a fazê-lo e seguir nossa inspiração como se o simples fato de dobrar à direita ou à esquerda já constituísse um ato essencialmente poético" ${ }^{\prime \prime}$, se deslocar e descobrir, em sua dimensão subjetiva, o inesperado. Nessa movimentação, há, evidentemente, o contato humano e cultural, pois a cidade "é o lugar onde há mais mobilidade e mais encontros" (SANTOS, 2004, p. 319). A paisagem urbana é algo a ser visto e lembrado, o cotidiano dos lugares, o pulsar das ruas e dos carros e ônibus que cruzam a cidade, a ordem e a desordem, enfim, uma coisa a ser percebida, a ser explorada, a ser visitada, a ser olhada, compreendida e sentida como concerto para o corpo e a alma. Pode-se dizer, assim, que a compreensão no ver, no olhar, para além do simples apelo ao visual, possui um valor e um sentido que ultrapassa o monumento em si e até mesmo as intenções de quem o criou, e acaba por despertar a fruição estética.

Por isso, contemplar lugares do cotidiano, o patrimônio urbano, para além de sua objetividade, leva-nos a ver a cidade como uma obra coletiva, permeada de representações simbólicas, pois, "na maioria das vezes, nossa percepção da cidade não é abrangente, mas antes parcial, fragmentária, misturada com concepções de outra

4 Flâneur, do francês, flanador, passeante, é aquele que anda pela cidade com atitude de interesse e curiosidade pelo que ocorre à sua volta.

5 Trecho do artigo de Edmond Jaloux (publicado em 1936, em Le Temps) e citado por Walter Benjamim em Obras escolhidas: Charles Baudelaire - um lírico no auge do capitalismo, vol. III. São Paulo: Editora Brasiliense, 1991, 2a . edição, p.210. 
natureza. Quase todos os sentidos estão em operação, e a imagem é uma combinação de todos eles" (LYNCH, 2010, p. 2). Acreditamos, assim, que cada pessoa tem a sua própria afinidade com lugares de sua cidade e a imagem deles é impregnada de lembranças e significados. As pessoas podem ter clareza de que há espaços na cidade que podem significar muito em termos de prazer cotidiano, mas não com a apropriação negligente, a exemplo do que fazem alguns agentes do turismo, que descuidam a comunidade e os lugares. Isso porque a atividade turística deve ser vista para além da dimensão material do espaço, pois o consumo turístico, muitas vezes alienado e alienante, se mostra incapaz de compreender a beleza que existe nos lugares públicos e na cultura local, elementos de composição da história do lugar. A partir dessa conscientização, os espaços e seus objetos devem ser vistos em função dos significados que lhes atribuímos, por intermédio de nossa subjetividade.

Isso é o que nos sugere ainda pensar como e de que forma conhecer a cidade além de seus monumentos, não apenas a cidade como uma coisa em si, mas seu patrimônio cultural pensado e consentido por seus habitantes e como um bem destinado ao usufruto de uma comunidade, pois aponta para modos de vida, práticas e relações sociais. Mas, antes restrito ao excepcional, patrimônio, hoje, expressa também a riquíssima diversidade incrustada em vidas cotidianas. Pode, assim, ser assimilado como produto cultural de importância e valor social, cultural e histórico e, por isso, relevante para ser visto e apreciado. Por isso, a cidade, a cultura, o patrimônio e o turismo não podem ser vistos, muito menos entendidos, independentemente, quando se tenta dimensionar o uso dos lugares para a atividade turística. Ainda que os termos carreguem um substrato político individual, eles devem ser vistos, para a apropriação do tempo livre, na dinâmica das relações que existem entre os lugares e suas necessidades materiais, imateriais, econômicas, sociais e culturais.

\section{REFERÊNCIAS}

BOTTOMORE, Tom (Ed.). Dicionário do pensamento marxista. Tradução Waltensir Dutra. Rio de Janeiro: Jorge Zahar Editor, 1988, 2a. edição

CHAUI, Marilena. Cidadania cultural: O direito à cultura. São Paulo: Editora Fundação Perseu Abramo, 2006.

DIAS, Karina. Entre visão e invisão: paisagem (por uma experiência de paisagem no cotidiano). Brasília: Programa de Pós-graduaçaão em Arte. Universidade de Brasília, 2010.

GASTAL, Suzana (Org.). Turismo: Investigação e crítica. São Paulo: Editora Contexto, 2002. 
GASTAL, Suzana e MOESCH, Marutschka. Turismo, políticas públicas e cidadania. Coleção ABC do Turismo. São Paulo: Editora Aleph, 2007.

GASTAL, Suzana (Org.). Turismo: 9 propostas para um saber-fazer. Coleção Comunicação. Porto Alegre: EdiPUCRS, 2008, 4a. edição revisada.

HARVEY, David. A produção capitalista do espaço. Tradução Carlos Szlak. São Paulo: Annablume, 2005, 2a. edição.

HALBWACHS, Maurice. A memória coletiva. Tradução Beatriz Sidou. São Paulo: Centauro Editora, 2011, 2ạ. edição, 5ạ. reimpressão.

LEMOS, Carlos A.C. O que é patrimônio histórico. São Paulo: Editora Brasiliense, 2010.

LYNCH, Kevin. A imagem da cidade. Coleção Mundo da Arte. Tradução Jefferson Luiz Camargo. São Paulo: WMF Martins Fontes, 2010, 2ạ. edição.

MAFFESOLI, Michel. No fundo das aparências. Tradução Bertha Halpern Gurovitz. Petrópolis: Editora Vozes, 2010. 4a. edição.

MAGALHÃES, Leandro Henrique. Discussão crítica acerca do turismo numa perspectiva materialista histórica. Caderno Virtual de Turismo. Vol.8, n ‥ 2, 2008, pp 95-104. UFRJ, p.96. http://redalyc.uaemex.mx/redalyc/pdf/1154/115415175009. pdf Consulta em 30/01/2013.

MARX, Karl e ENGELS, Friedrich. A ideologia Alemã. Tradução Luis Cláudio Castro e Costa. São Paulo: Martins Fontes, 2002.

MARX, Karl e ENGELS, Friedrich. Manifesto comunista. São Paulo: Boitempo Editorial, 2007, 1a. edição, 5ạ. reimpressão.

MOESH, M. "Para além das disciplinas: o desafio do próximo século". In GASTAL, Susana (Org.). Turismo, investigação e crítica. São Paulo: Editora Contexto, 2002.

MOESCH, M. O fazer-saber turístico: possibilidades de superação e limites. In GASTAL, S. (Org.). Turismo: 9 propostas para um saber-fazer. Porto Alegre: EdiPUCRS, 2008, 4ạ. edição revisada.

PELLEGRINI, Sandra C.A. e FUNARI, Pedro Paulo. O que é patrimônio cultural imaterial. São Paulo: Editora Brasiliense, 2008.

PELLEGRINI, Sandra C.A. e FUNARI, Pedro Paulo. Patrimônio histórico e cultural. Coleção Passo a Passo. Rio de Janeiro: Editora Zahar, 2009, 2ā. edição.

RUBIM, Antonio Albino Canelas. Políticas culturais entre o possível e o impossível. 
In Blog do Curso de Políticas Culturais do Instituto de Humanidades, Artes e Ciências Professor Milton Santos (IHAC-UFBA).http://politicasculturais.files.wordpress. com/2009/03/politicas-culturais-entre-o-possivel-e-o-impossivel.pdf. Consulta em 22/06/2012.

SANTOS, Boaventura de Sousa. Pela mão de Alice: O social e o político na pós-modernidade. São Paulo: Cortez Editora, 2101b, 13a. edição, 1a. reimpressão.

SANTOS, José Luiz dos. O que é cultura. Coleção Primeiros Passos. São Paulo: Editora Brasiliense, 2003, 16a. edição, 9a. reimpressão.

SANTOS, Milton. Testamento intelectual. São Paulo: Editora Unesp, 2004a.

SANTOS, Milton. A natureza do espaço. São Paulo: Edusp, 2004b, 4ạ. edição.

SANTOS, Milton. Pensando o espaço do homem. São Paulo: Edusp, 2009, 5a. edição.

SANTOS, Milton. O espaço do cidadão. São Paulo: Edusp, 2007, 7ạ. edição.

SANTOS, Milton. Por uma outra globalização: Do pensamento único à consciência universal. Rio de Janeiro: Editora Record, 2011, 20ạ. Edição.

SIQUEIRA, Deis. História social do turismo. Rio de Janeiro: Editora Garamond / Goiânia: Editora Vieira, 2005.

ULHÔA, Maria Inês A. Entre carnes e livros: a arte plural de um açougue e sua apropriação como patrimônio cultural. Brasília: Programa de Pós-graduação em Turismo. Universidade de Brasília (dissertação), 2013.

YÚDICE, George. A conveniência da cultura: Usos da cultura na era global. Belo Horizonte: Editora UFMG, 2004. 